\title{
Spatial Analysis of Educational Services Using GIS in Nasiriyah City
}

\author{
Khaldoon T. Falih ${ }^{1}$, Ahmed M. Alyaqoobi² \\ ${ }^{1}$ Petroleum Engineering College, Al-Ayen University, Dhi-Qar, Iraq \\ ${ }^{2}$ Dhi-Qar Directorate, Ministry of Planning, Dhi-Qar, Iraq
}

Article History: Received: 11 October 2020; Accepted: 27 December 2020; Published online: 8 February 2021

\begin{abstract}
Geographic Information Systems (GIS) are becoming useful and important tools for making strategic decisions whenever reliable data on spatial distribution are found, finding suitable sites for educational areas is important, as schools located in a strategic and safe area play an important role in building up students' skills in the future. The objective of the present work is therefore to firstly evaluate the educational services in Nasiriyah city in its regional context and to suggest educational services in the city of Nasiriyah in its regional context and to suggest long-term options for their development.Secondly, it aims to outline the measures necessary to ensure the orderly development of the expansion of educational needs within urban limits, and to provide for the Spatial analysis for education services in the city. The Geographic Information System (GIS) has been implemented as a multi-criteria spatial analysis tool. Results with some of the implemented standards based on (GIS) using ArcGIS 10.3 Network Analyst (Service Area) tool and Excel Office as statistical software.

Keywords: Geographic Information System, Spatial analysis, Spatial Distribution, Kindergartens, Primary schools, Secondary school.
\end{abstract}

\section{Introduction}

The development of Geographic Information System (GIS), spatial analysis and computer technology become an uncomplicated assignment for planners. Spatial analysis aims to identify the most appropriate spatial pattern for future site location according to specify requirements and preferences of some activities[1].GIS used to understand, analyze, and manage data spatially. Although it started with the purpose of creating digital maps, it quickly became a valuable tool in the decision making process for various educational services[2]. Systematic plan is one of the main factors that ensure a good quality in education development and wellequipped school site.The planning and distribution depends on several criteria like: the distance, population and other land use. Also taking into account the urban expansion in those areas and assessment of needs the future population in respect of educational services[3].educational sector is a critical issue for developing countries. Providing educational facilities by the government does not only mean developing schools, but also includes other services. These services involve developing a transportation network such as roads, adequate classrooms, sufficient number of teachers and good planning strategies[4].

This study is an attempt to clarify the GIS contribution to the analysis and evaluation of the reality of educational services (schools and kindergartens) in Nasiriyah city, as well as to make somesuggestions to the competent authorities in this vital sector in the belief that the important of GIS in the development process. Furthermore, using the to use the statistical analysis for thiseducational services.

\section{Case Study}

Al-Nasiriyah City, Center of Dh-Qar Provinceof the province of Dhi-Qar, is located in the south of Iraq, as shown in Figure (1), Al-Nasiriyah is one of the most important Cultural citiescenters in Iraq, the majority of which are very fertile agricultural. The governorate is famous for its Marsh area (Haur Al-Hammar) andUR Ziggurat which is important is important for the tourism industry. It could therefore be argued that the governorate has economic importance in terms of agricultural and tourism potential, including natural and historical/archaeological tourism. Its located at zone $(38 \mathrm{~N})$ according to UTM (Universal Transverse Mercator) geographic coordinate system between latitude $\left(30^{\circ} 40^{\prime} 00^{\prime \prime}\right.$ to $\left.32^{\circ} 00^{\prime} 00^{\prime \prime}\right)$ north and longitude $\left(45^{\circ} 40^{\prime} 00^{\prime \prime}\right.$ to $47^{\circ} 10^{\prime}$ $\left.00^{\prime \prime}\right)$ east. The city of Al-Nasiriyah has developed over the years in linear fashion to the west, while the area of Nasiriyah City (1277 sq. km) represents (31\%) the total area of the Dhi-Qar Government[5]. 


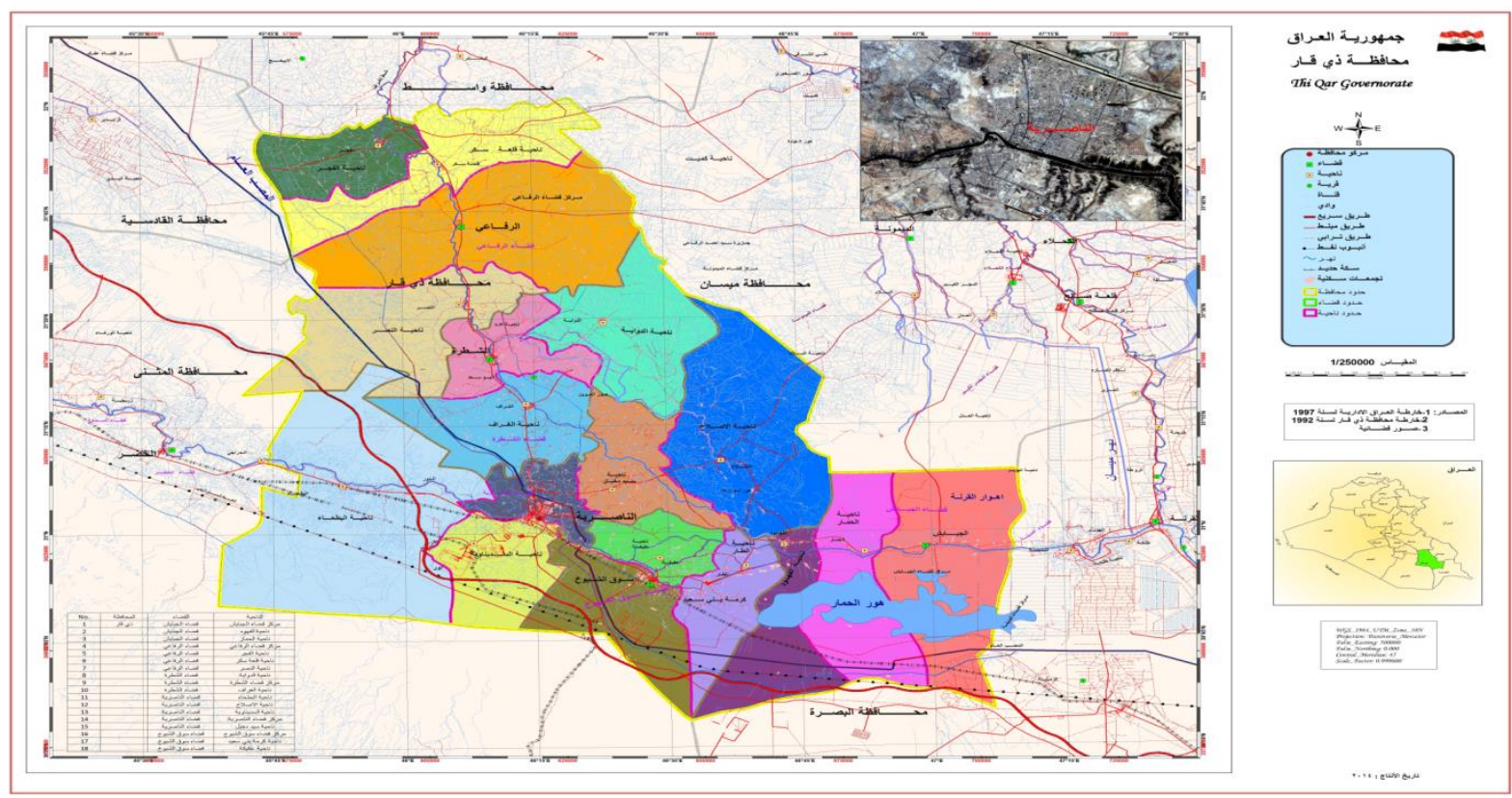

Figure (1):Dhi-Qar Governorate Map

\section{Problem Statement}

Because of the lack of geographical distribution of these facilities and some populated areas, after the establishment of schools and kindergartens in the city in recent years, which mainly concentrate on hustle and paralyzed traffic in many themes and main streets, there were not enough schools and kindergartens to accommodate the increasing of population, The criteria and requirements for the construction of education services, especially new ones, have not been taken into account. In order to reach all people in urban and rural areas, and to be far from roads and industry, the concept of equality must also be implemented in the provision of educational services.

\section{Research Methodology}

The research methodology was divided into five stages:

1-General Survey and Theoretical: This phase includes a survey of the field of study, concepts, models and theories related to the subject of this study.

2-Data Collection: This phase includes the collection of descriptive and spatial data, depending on the statics of the formalities, reports, interviews and observations.

3-Data Preparation: This stage includes data processing, coding and data entry, and data collection on digital maps and tables to be analyzed using Statisticdata mining and ArcGIS10.3 software.

4 - Spatial and Quantitative Analysis: at this stage, the current reality of the distribution of education services has been analyzed and the problems and vulnerabilities faced by the development of proposals and appropriate solutions and perceptions of the future have been identified.

5-Conclusions and Recommendations: this stage evaluates the results and develops recommendations to address the challenges of the education services sector.

\section{Iraqi criteria for the distribution of education services}

The planning process for the establishment of schools at the site depends on many conditionsconditions. It is not important to set up a school wherever it may be without taking into account the criteria that must be applied. The Iraqi Ministry of Planning has defined a set of criteria for establishing schools within the urban space, as these criteria are built on the basis of the number of beneficiaries and the distance (meters) that students travel to reach their schools, which is known as (accessibility), time (minutes) the student takes to arrive, known as (arrival time) as well as adopting the concept of neighborhood in the distribution of schools within a specific spatial space[6,7,8], this criteria shows in Table (1). 
Table (1):standard criteria for educational services (schools and kindergartens)

\begin{tabular}{|c|c|c|c|}
\hline education requirement & $\begin{array}{c}\text { Standard value } \\
\text { kindergartens }\end{array}$ & $\begin{array}{c}\text { Standard value } \\
\text { primary school }\end{array}$ & $\begin{array}{c}\text { Standard value } \\
\text { secondary school }\end{array}$ \\
\hline $\begin{array}{c}\text { Distance from residence to school } \\
\text { (meter) }\end{array}$ & 300 & 500 & 850 \\
\hline $\begin{array}{c}\text { arrival time from residence to } \\
\text { school(minute) }\end{array}$ & $----15-8$ \\
\hline Number of pupil per school & 140 & 360 & 540 \\
\hline Number of pupil per teacher & 18 & 30 & 25 \\
\hline Number of pupil per class & 30 & 30 & 30 \\
\hline Area for each pupil & 3500 & $3-3.5$ & $1.4-2$ \\
\hline Plot Area (m2) & & 5000 & 8000 \\
\hline
\end{tabular}

\section{The reality of education inNasiriyah City}

Education constitutes an important part of the social infrastructure in Al-Nasiriyah city. There are 440 schools with different levels of education[9]. While the number of buildings dedicated to educational services (kindergartens and schools) 150 buildings onlyas shown in the Table (2), The distribution of these services is illustrated as Figure 2 .

Table (2):Statistics for the preparation of schools and kindergartens in the city

\begin{tabular}{|c|c|c|c|}
\hline Education Services & No. of Schools & No. of Buildings & Area $\left(\mathrm{m}^{2}\right)$ \\
\hline kindergartens & 12 & 12 & 3500 \\
\hline primary school & 315 & 87 & 5000 \\
\hline secondary school & 113 & 51 & 8000 \\
\hline
\end{tabular}

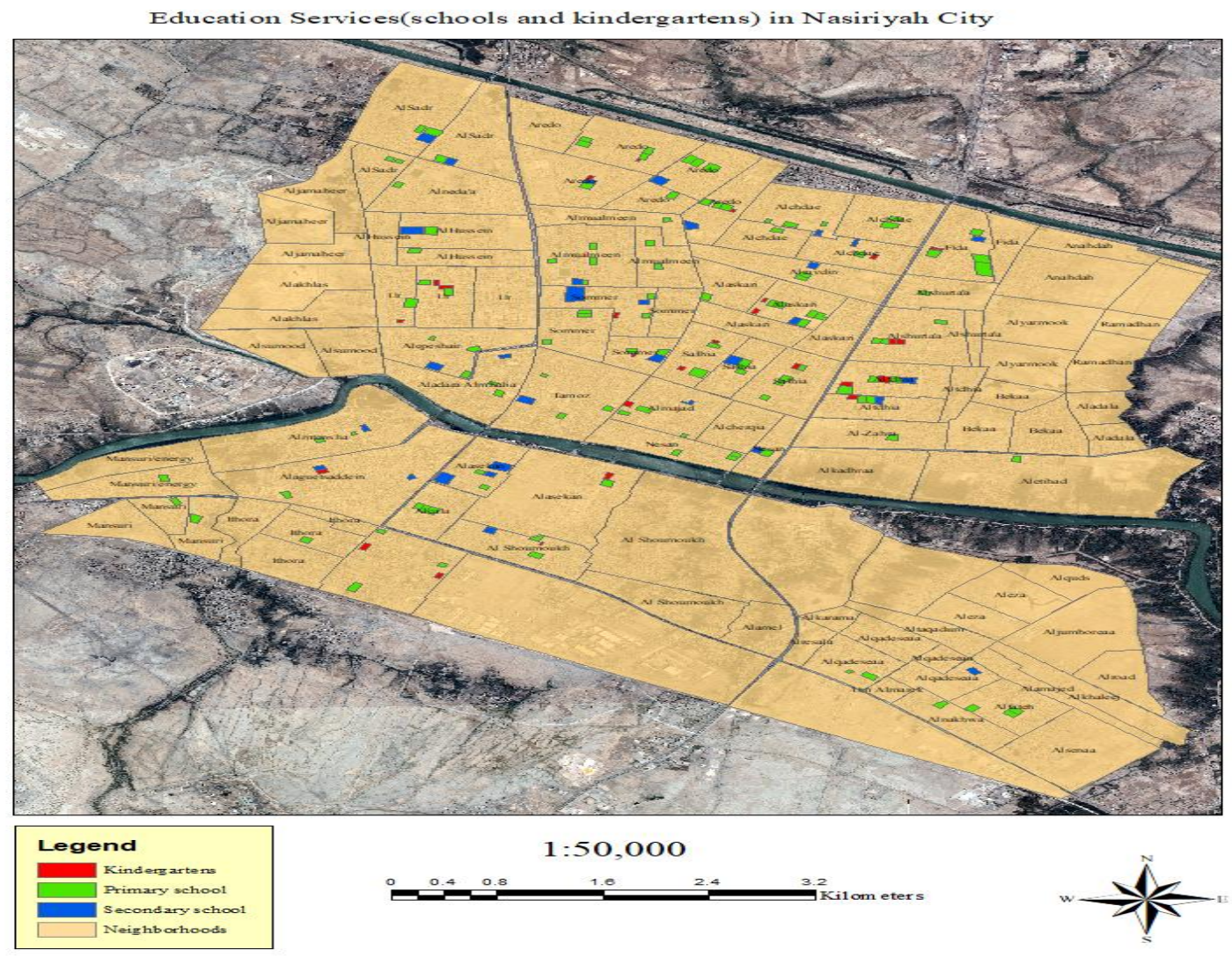

Fig.(2):Education Services (schools and kindergartens) in Nasiriyah City Directed by Researcher 


\section{Demographic description}

Educational services in Nasiriyah have been affected by Populational Growth, which reached (573148) inhabitance in 2019[10]. This increase is also reflected the increasing number of residential sectors with 111 residential districts and their area $(687 \mathrm{Km} 2)$. This increase is offset by the lack of development of education services in accordance with international standards.. When conducting surveys, in cooperation with the competent departments, data were found to prepare students as shown in the Table(3)

Table (3):No. of student in Education Services (schools and kindergartens) in the city

\begin{tabular}{|l|c|}
\hline \multicolumn{1}{|c|}{ Education Services } & No. of students \\
\hline kindergartens & 2864 \\
\hline primary school & 129145 \\
\hline secondary school & 56042 \\
\hline
\end{tabular}

\section{Educational services}

Educational services are one of the important pillars that help to discover the students' intellectual and mental energies, so they are among the services that must be provided in the city. On these services, the city relies on crystallizing an educated and conscious generation, and the educational process also helps prepare students and makes them gain great experience in various scientific fields .For the purpose of determining the efficiency of the distribution of educational services spatially and the nature of their performance, by comparing their current indicators with the approved local planning standards [4].After conducting surveys for educational services and comparing the current reality of educational services with the criteria that were defined in the previous paragraphs,Below we will include surveys of educational services and their analysis:

\subsection{Kindergartens}

The general planning standard specified one kindergarten for every 3600 inhabitants, and accordingly, the city needs (159) kindergartens, while there are only 12 kindergartens available, so that the development gapis 147 kindergartens.The statistical analysis of educational services for kindergartens with related indicatorsare shown into Table (4). It comes as follows:

1-Based on the indicator (1 Teacher / 18 Students), there is a deficit in teachers of kindergartens reached 52 teachers in the city.

2-The increasing rate per one classroom according to the indicator (1 classroom / 30 children) was 12 students.

3- The gap in the number of classrooms according to the indicator ( 1 classroom /30 children) was 47 classrooms.

Table (4):Indicators of educational services for kindergartens

\begin{tabular}{lc}
\hline Population (people) & 573148 \\
\hline Area km ${ }^{2}$ & 687 \\
No. of Pupil & 2864 \\
No. of Buildings & 12 \\
No. of classrooms & 48 \\
No. of Classrooms as per indicator (1 kindergarten / 5 class ) & 60 \\
Deficit of classrooms & 12 \\
No. of teacher & 107 \\
No. of teacher depend (1 teacher / 18 Pupils ) & 159 \\
Gap in No. of teachers & 52 \\
No. of classrooms & 48 \\
No. of Class as per indicator (1 classroom / 30 Pupils ) & 95 \\
Deficit of classrooms & 47 \\
Student increasing rateinto one classroom & 12 \\
\hline
\end{tabular}




\subsection{Primary Education}

The general planning standard specified one school for every 2,500 people of the population, and accordingly, the city need (229) primary schools, while there are 315 of them are available, which reflects the existence of a surplus of 86 primary schools according to this criterion, which looks at the number of schools regardless of the existence of independent buildings and regardless of the actual number of students. The statistical analysis of educational services for primary schools with related indicatorsis shown into Table (5). It comes as follows:

According to the indicator _ a school for every 360 pupils _ the city recorded a total deficit of school buildings for primary education by $2 \overline{7} 2$ school buildings.

The deficit in the number of classrooms according to the indicator - classroom for every 30 pupils-is recorded to 985 classrooms throughout the city.

Primary schools in the city recorded a surplus in the number of teachers according to the indicator - one teacher for every 30 pupils - and a total surplus of 2,493 teachers throughout the city.

Table (5):Indicators of educational services for kindergartens

\begin{tabular}{lc}
\hline Population (people) & 573148 \\
\hline Area km² & 687 \\
NO. of Buildings & 87 \\
No. of school depend (360 pupil / 1 School ) & 359 \\
Gap in No. of School & 272 \\
No. of Pupil & 129145 \\
No. of teacher & 6798 \\
No. of teacher depend (1 teacher / 30 Pupils ) & 4305 \\
Gap in No. of teachers & -2493 \\
No. of classrooms & 3320 \\
No. of Classrooms depend (1 class / 30 Pupils ) & 4305 \\
Deficit in No. of classrooms & 985 \\
\hline
\end{tabular}

\subsection{Secondary Education}

Secondary education means intermediate and preparatory stages. Based on the general planning standard that defined a secondary school for every 10,000 inhabitants, the city needs (57) secondary schools. while there are 51 of them are available, which means there is a deficit of 6 building only. This criterion is not looking to the actual number of students. The educational services for secondary education, according to the statistical analysis of the secondary educationbased on the related indicators is shown into Table (6).It comes as follows:

According to the indicator ( a school for every 540 students), the city recorded a total deficit in the number of school buildings for secondary education by 52 school buildings.

The deficit in the number of school classrooms according to the indicator (one classroom per 30 students) was 579 classrooms throughout the city.

Secondary schools in the city recorded a surplus in the number of teachers by (817) extra teachersbased on the indicator ( one teacher for every 25 students).

Table (6):Indicators of educational services for kindergartens

\begin{tabular}{lc}
\hline Population (people) & 573148 \\
\hline Area km² & 687 \\
No. of student & 56042 \\
NO. of Buildings & 51 \\
No. of secondary school depend (1 school/ 540 student ) & 103 \\
Gap in No. of secondary school & 52 \\
No. of teacher & 3059 \\
No. of teacher as per the indicator (1 teacher / 25 student) & 2242 \\
Deficit in No. of teachers & -817 \\
No. of classrooms & 1289 \\
No. of Classrooms depend (1 class / 30 student ) & 1868 \\
\hline
\end{tabular}




\section{Use of GIS in education planning}

GIS is a system for storing, analyzing, managing and presenting data and maps of associated attributes as spatial information that is spatially linked to the Earth's surface[12], which relates to all the features and processes that occur on the Earth's surface. Information is at the heart of geographic information systems, where an enormous amount of data and analysis is stored.In many developed countries around the world, GIS is a trend towards the use of geographic information systems and educational mapping facilities to support decision-making, particularly in the Ministry of Education[13]. Educational services planning encompasses a wide range of educational planning and management issues, relates to the allocation of resources and efficiency in the delivery of services and improves the efficiency of learning, mapping is a tool commonly used to detect relationships between educational institutions and the distribution of the population of school age.The availability of a comprehensive framework and spatial planning database, as well as non-spatial data, has become a tool to assist in the planning and decision-making, mapping of kindergartens and schools, along with information on administrative boundaries and physical layers such as the main road network and the reality of the earth in terms of geographical coverage[4].

\subsection{Determine the efficiency of the spatial distribution}

Analysis of spatial data such as distribution style using spatial statistics tools (Network Analyst-Service Area and Analysis Tools), nearest neighbor and arrival time using spatial statistics pattern analysis (Distance from residence to school and time to arrival). All of these techniques are available in the ArcMap10.3 software. .$[14,15]$

A database has been created within the GIS program, which includes several layers:

- $\quad$ Satellite image Quick bird with Resolution $(50 \mathrm{~cm})$

- The internal transport network is equipped with a number of parameters including (Street Width - Street Length - Street Name - Street Type .... etc)

- $\quad$ Educational services locations by type (Kindergartens, Primary school and Secondary school)

- Residential units in the city.

The Network Analyst (Service Area) tool was used to analyze the ability to determine the scope of services using a distance factor that determines the areas that this service reaches or not.

\subsubsection{Spatial Distribution for kindergartens}

The accessibility of access will be analyzed by the factors of distance between the residence of the student and the kindergarten. Criteria for this analysis were used as shown in Previous Table (1) and the results after the analysis were shown in Figure (3). 


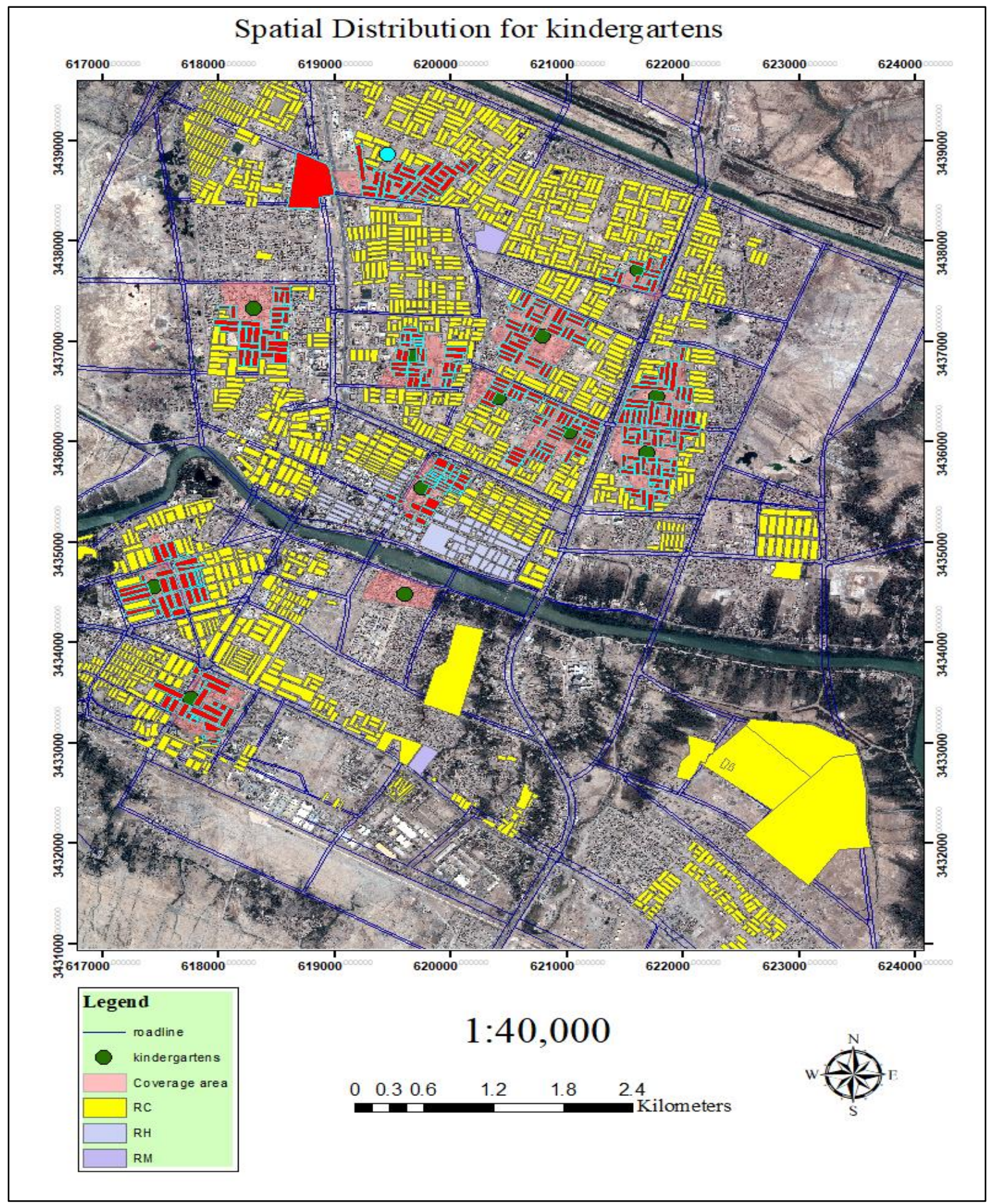

Figure (3) : Efficiency of spatial distribution for kindergartens

In addition to the apparent shortage in the number of kindergartens in relation to the population, we note from the above-mentioned figure the poor spatial distribution of the kindergartens, as we note that they only cover residential areas of red color, which represent only $20 \%$ of the city's residential areas.

9.1.2 Spatial Distribution for primary school

The data mentioned in Table (1) use distance from residence to school to analyze the distribution of primary school, where the coverage range was used for this type 500 meters and the results as shown in the following map Figure (4). 


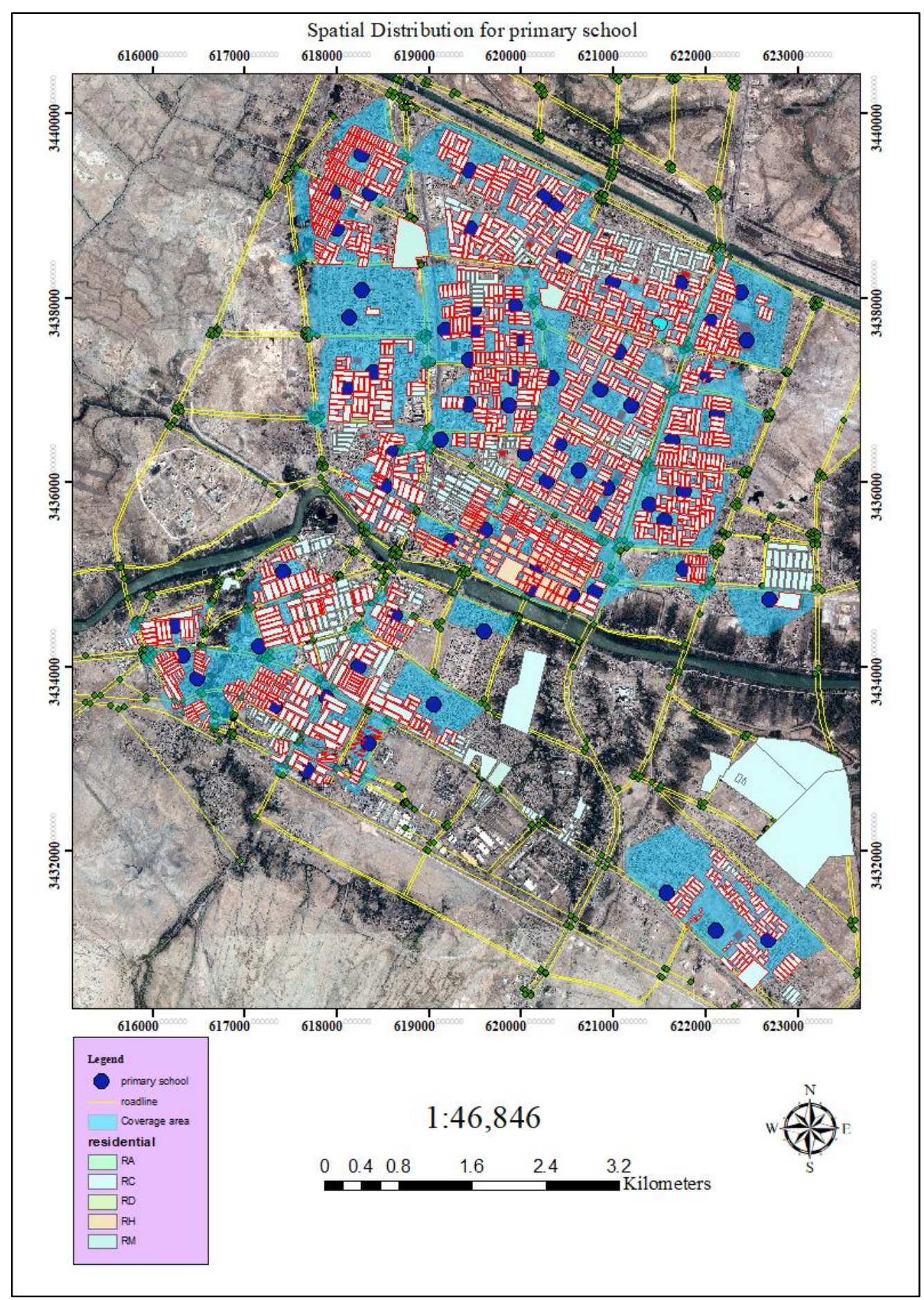

Figure (4) : Efficiency of spatial distribution for primary school

The spatial distribution of primary schools is very good, but, as previously mentioned, the number of schools is few relative to the population of the city.

9.1.3 Spatial Distribution for Secondary school

Accessibility will be analyzed by the distance factors between the student's residence and the secondary school, using $850 \mathrm{~m}$ as shown in the previous Table (1). The results of the analysis were shown in Figure (5). 


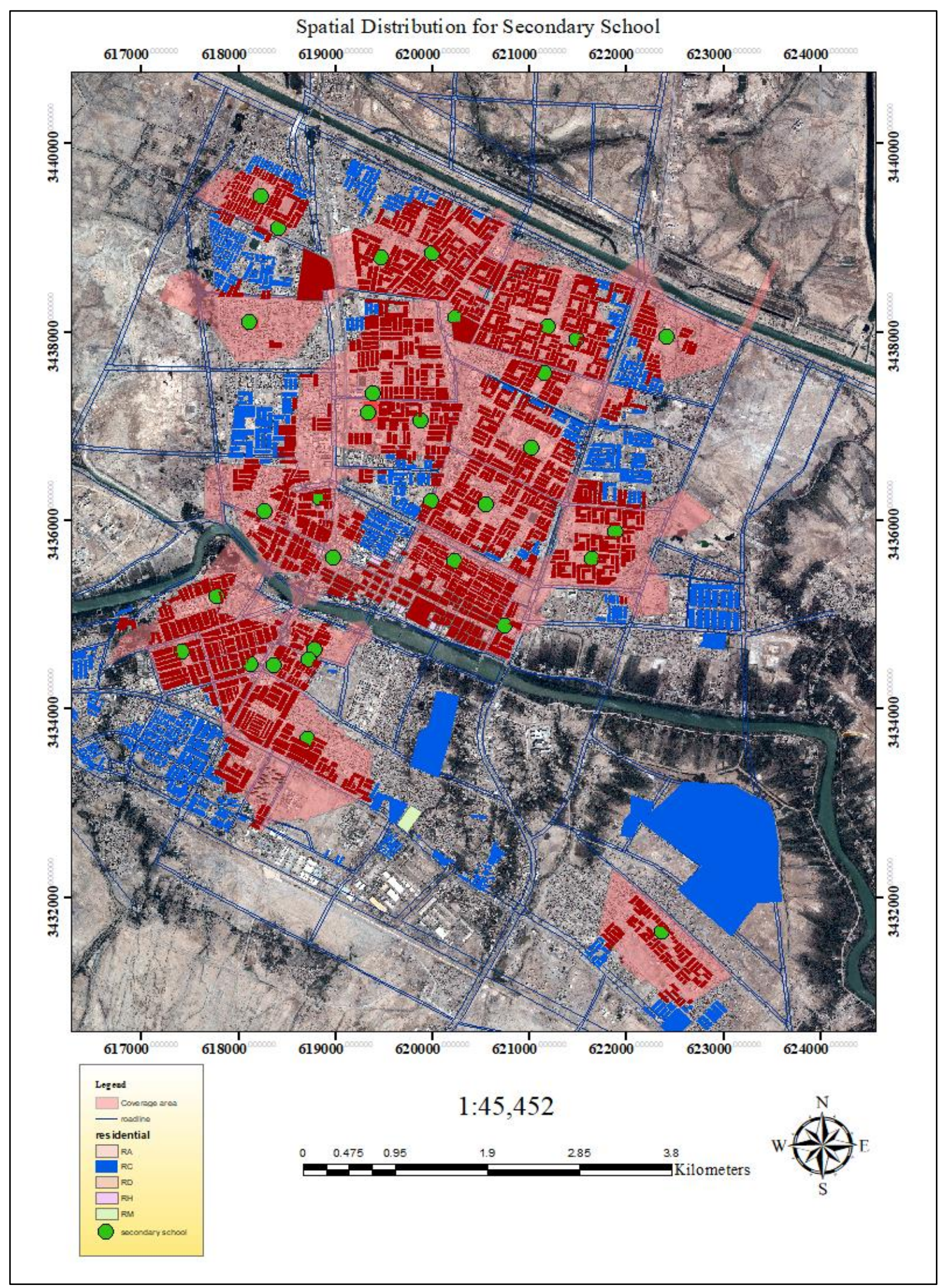

Figure (5) : Efficiency of spatial distribution for primary school

From the figure above, the distribution is somewhat acceptable due to the emergence of areas lacking secondary schools and colored in blue, which makes it easier for decision-makers to choose the most appropriate place to add a number of these schools. 


\section{Conclusion}

Through the study and evaluation of the reality of educational services (schools) in the city of Al-Nasiriyah. This research will includes two parts to results:

The first part of the results is the results of the statistical analysis that found:

1- Through the surveys conducted for the numbers of kindergartens and schools, it was found that there is a clear weakness in the numbers compared to the population census of the city, where the actual number reached: kindergartens (12), primary schools (315) and secondary schools (113(.

2- After taking the international requirements for the planning of educational services into account, the city needs: (159) kindergartens , (229) primary schools and (57) secondary schools.

3- Research studies have shown that one school or kindergarten building has more than one period for students, which reduces the school building's efficacy. Moreover, this is a direct indicator of the deficit of school buildings in terms of number.

The second type of the results is the results of the spatial analysis:

1- Spatial analysis processes for the distribution of educational services, used the distance factor for the analysis, and the results were as follows: The distribution is very poor for kindergartens, given their small numbers, the distribution to primary schools was very good and the distribution to secondary schools was somewhat acceptable.

2- Depending on the standards and tools used in GIS, we notice that some neighborhoods have overcrowding in schools at the expense of some neighborhoods that lack schools or a clear shortage in them.

\section{Recommendations}

For the above Conclusions, the current distribution of schools is not ideal and does not match the approved criteria, so the research recommends the following:

1- The redistribution of existing schools takes into account the distance and time of arrival requirements, as well as the demographic and school criteria for separating the original schools from other schools when selecting their locations.

2- The construction of new schools also takes into account the distance and arrival criteria, as well as the population and school criteria, to meet the actual need for educational services in some neighborhoods of the study area.

3- In addition, school spaces should be compatible with their grades, and with the number of students in them, so that their efficiency increases upon analysis

4-When designing buildings, consideration must be given to typical designs in terms of number of people, green areas and all other requirements.

\section{References}

A. Mohammad A. Rob. (2003). " Applications of Geographical Information Systems in Understanding Spatial Distribution of Asthma" . Informing Science Journal Vol. 6.

B. Bukhari , Z., Rodzi A. M., Noordin A.(2010)."Spatial multi-criteria decision analysis for safe school site selection". International Geoinformatics Research and Development Journal Vol. 1, Issue 2.

C. U. M. Mörtberg, B. Balfors, and W. C. Knol. (2007)."Landscape ecological assessment: A tool for integrating biodiversity issues in strategic environmental assessment and planning" Journal of Environmental Management, vol. 82, no. 4, pp. 457-470.

D. Nigig, M., Musiega, D. and Mulefu, F. (2012)." Planning and Analysis Educational Facilities using GIS", conference. AGSE.

E. COSIT. (2005): ILCS Vol II Analytical Report:"Iraqi Living Conditions Survey". Baghdad, Ministry of Planning and Development Cooperation.

F. Aliyu, A., Shahidah, M.A.,andAliyu, R.M. , "Mapping and Spatial Distribution of Post Primary Schools in Yola North Local Government Area of Adamawa State, Nigeria," International Journal of Science and Technology Volume 2 No. 5, ,ISSN 2049-7318, May 2013.

G. Amuyunzu, C.L and Bijl, B.C, "Integration of Remote Sensing and GIS for management, decision support in protected areas FUTY, "Journal of the Environment, Volume 1, NO. 1, 1999.

H. Ministry of Construction\& Housing (2010) : " Urban Housing Standards Manual ". State Commission of Housing, Studies Section

I. Ministry of Education ,Directorate of Education in DhiQar Governorate, Nasiriyah Education Department, Education Services Statistics 2019.and Dhi-Qar Directorate, Ministry of Planning 2019.

J. COSIT. (2019): " Population Estimates of DhiQar For the year 2019". Directorate of Population and La- 
bor Force Statistics, Table No. 20, 35".

K. Yousef, Taher (2007). " Spatial Analysis of Educational Services in Nablus City Using GIS Technology". Master Thesis, An-Najah National University.

L. O. ERAY, -Application of Geographic Information System (GIS) in Education, \| Journal of Technical Science and Technologies, vol. 1, no. 2, pp. 53-58, 2013.

M. M. G. Korucu, -GIS and Types of GIS Education Programs, \| Procedia - Social and Behavioral Sciences, vol. 46, pp. 209-215, 2012.

N. Shawky MANSOUR (2016): "Spatial analysis of public health facilities in Riyadh Governorate, Saudi Arabia: a GIS-based study to assess geographic variations of service provision and accessibility".Geospatial Information Science, 19:1, 26-38, DOI: 10.1080/10095020.2016.1151205

O. Khaldoon T. Falih, Ali Al Saedi (2020): " Evaluating the Distribution of Health Services in Nasiriyah City By Utilizing Geomatics Techniques "IOP Conference Series: Materials Science and Engineering , vol 928 , https://iopscience.iop.org/article/10.1088/1757-899X/928/2/022062/meta 